\title{
Clinical practice and epidemiology: two worlds or one?*
}

\author{
E D ACHESON
}

British Medical fournal, 1979, 1, 723-726

Like Josiah Wedgwood before him, Adolf Streicher was a man of ideas who was born before his time. Streicher would have appreciated the considerable innovation which the creation of this new centre for research in industrial and community health represents. He took an active interest in craft education and training, in health at work and other social aspects of industry long before such matters were accepted as a normal part of an employer's responsibility. Here, for the first time, so far as I know, guided by the leadership of a small band of medical men, public impulse and private subscription have recognised epidemiology as an important tool in helping to solve contemporary problems of health and sickness. Dr Sam Cole, its director, has given me permission to quote from the proposal which he drafted and which was later accepted as the basis for the centre. He wrote: "Fundamentally we recognise a general need for using epidemiological methods to identify those aspects of common diseases which may be amenable to prevention or to new methods of medical care, and thereby lighten the burden of ill health upon the individual and the community."

Another unique feature of the centre is that it excludes no one. Not only specialists in community and occupational medicine but clinicians have been concerned from the inception in its development, and all will be encouraged to use its facilities for research. Here in the Potteries much of the impetus for the centre has stemmed from general awareness that illness and suffering attributable to occupation have gone hand in hand with the benefits of the ceramic craft. With this in mind, I have chosen

*Paper prepared for the inaugural Adolf Streicher Lecture, delivered at the opening of the Industrial and Community Health Research Centre, the North Staffordshire Medical Institute, on 5 December 1978.

\footnotetext{
University Department of Community Medicine, General Hospital, Southampton SO9 4XY

E D ACHESON, FRCP, FFCM, professor
}

several of my examples from occupational medicine. But the aims of the centre are not parochial. There is a clear intention to take advantage of the stable population and the outstanding medical services and computer facilities in North Staffordshire to tackle by epidemiological methods some of the problems that beset the country as a whole, including those of iatrogenic illness, the development of effective methods of education for healthy living, and the prevention of dependence in the elderly.

\section{Defining epidemiology}

What then is this epidemiology that seems to have caught the public imagination in North Staffordshire? The definition that I prefer personally is that epidemiology is the study of the distribution of disease and of its determinants in populations. As Morris has pointed out, epidemiology has many uses, most of which are directly relevant to clinical practice. ${ }^{1}$ In this essay I will limit my attention to one, namely its use in unravelling the causes of disease.

From the point of view of the public good, one of the practical implications of epidemiology is that the study of external influences may make prevention possible, sometimes even when the pathogenesis of the disease concerned is not clearly understood. But that does not mean that epidemiology is in some way opposed to the study of mechanisms or, conversely, that knowledge of mechanisms is not sometimes crucial to prevention. Thus poliomyelitis and diphtheria are preventable as much because of knowledge of the microbiological mechanisms concerned as of their epidemiology. In my view insight into pathogenesis (mechanisms) and into external causes (aetiology) usually go hand in hand. In the case of multiple sclerosis we can now see in retrospect that early epidemiological work was seriously handicapped by ignorance of genetically controlled immunological mechanisms associated with the presence of certain of the histocompatibility antigens. ${ }^{2}$ By using these immunological techniques, it may in future be possible to concentrate epidemiological inquiry on subgroups of populations 
that are susceptible to the disease to determine how susceptible people who suffer from it differ from those who do not.

About the time that Josiah Wedgwood was opening his famous factory at Etruria for the manufacture of jasperware one of the classic epidemiological adventures was being enacted in another part of England. In 1767 Sir George Baker published his celebrated essay on the Devonshire colic. ${ }^{3}$ The starting point of his reasoning was the observation that the clinical symptoms and signs of the sufferers-namely, colic, paralysis, and epilepsy -were identical with those he had observed elsewhere in patients with lead poisoning. Inquiries revealed that lead was used in the cider presses in Devonshire but not in Herefordshire. Furthermore, in Herefordshire colic among cider drinkers was rare. Chemical analysis confirmed the presence of lead in Devonshire cider but not in that from Herefordshire. The case was finally clinched by the fact that the disease disappeared when the lead presses were removed.

\section{Epidemiology and clinical medicine}

How deceptively simple it all sounds in retrospect. Of the many lessons one may draw from the story of the Devonshire colic I wish to emphasise only one. Baker's discovery exemplifies the two essential elements in epidemiology-namely, counting people in populations and medical knowledge. Admittedly in Baker's case the counting hardly amounted to a formal survey, but it did entail a comparison between the proportions of sufferers in two populations in the two counties. The starting point of the whole adventure had been the recognition of a characteristic clinical pattern.

Let us now move forward in time almost two hundred years to a subject that would have had a special interest for Adolf Streicher. I refer to occupational cancer of the interior lining of the nose and ethmoid air sinus. In 1964 Miss Esme Hadfield and her colleague Ronald Macbeth reported 20 cases of intranasal cancer from their clinic in High Wycombe; they also noted that no fewer than 15 of the men were makers of wooden chairs. ${ }^{4}$ In this instance it was not the clinical pattern of the illness that started their train of thought but the intuition that there was something unusual about the pattern of occurrence of the disease in the population. They knew that nasal cancer is rare and too many cases seemed to be occurring in High Wycombe. The ratio of wood workers to other men also seemed odd. Were they observing an epidemic in wood workers, they wondered. As is well known, formal epidemiological surveys confirmed the existence of a high risk of nasal cancer in furniture workers, and by analysing the pattern of occurrence of the tumours in the factories it was possible to show that the dust of the wood itself probably contained the carcinogen, not the sprays, polishes, or adhesives applied to it. ${ }^{56}$

The difference between the starting points of the two epidemiological stories I have quoted from is this. In the case of the Devonshire colic the existence of recurrent epidemics was well known, but they had been incorrectly attributed to the acidity of the cider. Baker contributed as a clinician by recognising in the patients the clinical pattern of lead poisoning and as an epidemiologist by making a comparison between two populations to test his hypothesis. Hadfield and Macbeth's contribution was to recognise for the first time the existence of an epidemic of cluster of cases.

\section{Observation and luck}

This brings me to another fundamental point about the relation of epidemiology to clinical medicine. It is the clinical practitioner (in the widest sense of that term) who usually has the best opportunity to observe the cluster of cases which sets the ball rolling. To provide evidence to substantiate this point, I will take as my example carcinogenesis and consider those factors excluding carcinogenic drugs that are known to have exerted a carcinogenic action in man. Of the 19 factors listed in the table, no fewer than 13 were first brought to attention by the observation of a cluster of cases by an alert clinician. In only three (mustard gas, 4-aminodiphenyl, and vinyl chloride) work in animals first showed the substance concerned to be carcinogenic and a subsequent search for an appropriate exposed human population turned up cases in man. In two others (tobacco and alcohol) the hypothesis arose from a consideration of trends and the risks of a wide range of populations. In other words, in two instances only, the idea emerged at the desk rather than in the clinic. The final instance (dust in the boot and shoe industry) was discovered largely by luck. I will be returning to the importance of luck in all this in a moment.

Nineteen factors known to have exerted carcinogenic action in man

Polycyclic hydrocarbons
Asbestos
Ionising radiation
Ultraviolet light
Arsenic
Wood dust
Isopropyl oil
Nickel
Benzene
Radium

Aromatic amine Chrome Bichloromethyl ethe Mustard gas 4-aminodipheny Tobacco $\mathrm{C}_{2} \mathrm{H}_{5} \mathrm{OH}$ (ethyl alcohol) Leather dust

The study of carcinogens represents only one aspect of epidemiology and the question may reasonably be asked whether it is a special case. So far as drug-induced illness and illnesses due to environmental toxins, such as lead, arsenic, and so on, are concerned the clinician is in at least as favourable a position to make the crucial observation that starts the intellectual hue and cry, as he is in respect of carcinogens. But where a widespread change in the environment (perhaps due to a change in diet or lifestyle) is responsible for the appearance of illness significant clusters-that is, clusters that point to a causative factor-may be hard to detect. But even then, study of a group who for religious or other reasons live according to a discipline that differs sharply from the norm-for example, strict vegetarians or Seventh Day Adventists-may yield important clues.

Basically the problem is one of contrast. If tomorrow morning one looks out at a bird table and sees two cockatoos it is immediately apparent that something extraordinary is happening. But if 40 sparrows instead of the usual 20 are there this will almost certainly escape notice. Two points seem to matter: the first and less important is the surplus or excess of what one observes compared with what one expects to observe. The second and more important factor is the size of the number one expects, or to put it another way the rareness of the event in general: the rarer the event the easier (usually) it is to spot a cluster of such events. Thus two cases of angiosarcoma of the liver in men working in a factory are much more likely to be spotted than a numerically much more important doubling of the number of cases of lung cancer from 20 to 40 . This is because angiosarcoma of the liver is so rare, only a handful of cases occurring in Britain each year.

The next point I want to make is that many, if not most, of the clusters that have been spotted so far and have led to the identification of a causative factor have been cockatoos rather than sparrows: cancer of the scrotum in chimney sweeps observed in the nineteenth century by Percival Pott was definitely a cockatoo, so was mesothelioma and its relation to asbestos; the peculiar skin cancer associated with arsenic; nasal cancer and wood dust and leather dust; bone cancer in people using radium to luminise watch dials; benzene and leukaemia; and outside carcinogenesis, phocomelia in the children of women who had taken thalidomide was a cockatoo, and so was the characteristic pattern of congenital malformations seen in the children of women who have German measles in pregnancy. In every instance the crucial observation was made because the cluster stood out against a background where the occurrence was rare. 
But how many cockatoos are as yet unidentified; and how about the unrecognised excesses of sparrows? I have little doubt that there are flights of cockatoos as well as flocks of sparrows still undiscovered in the woods of North Staffordshire and elsewhere. If one looks carefully at the discoveries I have already quoted, one is struck by two things. The first is how often extraneous factors helped to bring the epidemic to notice in the first place. For example, Gregg working in his clinic in Sydney, Australia, in 1941 might not have noticed the relation of German measles in early pregnancy to congenital malformations in babies if an epidemic of rubella had not coincided with an epidemic of marriage and conception associated with the imminent departure of the Australian expeditionary force for the Middle East. ' If the High Wycombe chair-making industry had been spread through the East End of London instead of concentrated in a single small town with one clinic for diseases of the ear, nose, and throat, the relation between nasal cancer and wood dust would still be unknown. So would the relation of dust in the boot and shoe industry to nasal cancer. That discovery depended on the coincidence that Northamptonshire, with its concentration of the boot and shoe industry, happens to be in the same Health Service region, and therefore shares the same cancer register, as Buckinghamshire. If Northamptonshire had been in the Trent region this association would probably remain undiscovered to this day.

When Case and Hosker were studying bladder cancer using hospital records of workers in the chemical industry they noticed that some patients with this condition worked in a different factory in the rubber industry in Birmingham. ${ }^{8}$ Subsequent inquiry showed that the suspected substance was present not only in the dyestuffs industry but was also used in the manufacture of rubber to prevent the tyres from perishing and was associated with a high risk of cancer in that industry as well. But for the chance selection of Birmingham as one of the centres in the national survey, it is doubtful whether this would have been spotted. The prominence of luck and special circumstances in so many of the discoveries to date must surely mean that a more general awareness would yield many more.

\section{Identifying disease patterns}

If you accept my reasoning that many undisclosed clusters of disease exist, how then should we spot them ? Basically, it seems that we should seek to identify favourable conditions for study, do what we can to increase awareness of our opportunities, and sharpen up the contrast, so that clusters of cases stand out more clearly against the background. My first suggestion is that we should try to establish as completely as possible the profile of illness of the city or area in which we practise, relative to the rest of the country. For example, as part of its area mortality analysis the Office of Population Censuses and Surveys publishes statistics for each of the county boroughs of England every 10 years. ${ }^{9}$ To take the Potteries as an example, there are several conditions for which the mortality in men and in women living in Stoke is substantially higher than for England as a whole. Of these, stomach cancer is particularly interesting because a relation between the national mortality pattern of this condition and exposure to dust in industry has recently been found. ${ }^{10}$

Obviously mortality statistics can help only in drawing out the patterns of fatal diseases. By the ingenious use of $x$-rays and laboratory tests carried out for routine clinical purposes and by inviting the co-operation of clinicians to set up registers of newly diagnosed cases of particular diseases in towns in various parts of England, ${ }^{11}$ Barker has recently shown how the geographical pattern of non-fatal diseases can be studied. For example, the prevalence of Paget's disease of bone in central and northern England varies in an interesting manner. ${ }^{12}$ The prevalence of the disease is highest in Lancaster and Preston, but declines sharply in the towns to the north, south, and east. Other evidence suggests that the prevalence of Paget's disease is decreasing with time. Perhaps we should be trying to identify environmental factors that were concentrated in Lancashire at the beginning of the century but are now declining.

I do not wish to suggest that all or even most of our ills come from industry and the effects of industrialisation. Nevertheless, occupation is specially interesting to epidemiologists because people are sometimes exposed in the workplace to higher doses of a substance or to more extreme conditions than outside it. If as clinicians we wish to spot significant clusters of illness, we will do well to have as intimate a knowledge of industry in the area in which we work as possible, and to record occupational histories in as much detail as time permits.

Age is another point to take into account. If a succession of cases of a disease occurs in younger people than is usual, this may be worth looking into. People may have been exposed to high doses of a substance and to one that has been introduced relatively recently into the environment. There are two other possible types of clue for which we should be on the lookout. The first, and this relates to cancer epidemiology in particular, is an unusual distribution of the different histological types of tumour of a particular site. Surgeons who have moved from the north to the south of England have told me that the proportion of gastric cancers of the scirrhous and leatherbottle variety varies in different parts of the country. It may be worth looking at the geographical pattern of such cases separately. Different histological types of tumour may have different causes. Secondly, the game may also be given away by an unusual combination of diseases in a group. The first indication of carcinogenicity of asbestos in man came from the observation that men with asbestosis seemed to die more frequently of lung cancer than was expected. This observation was made at a time when tobaccorelated lung cancer was still relatively uncommon. ${ }^{13}$

\section{Demography and medical knowledge}

Some people will, I suspect, have regarded my statement of the essential ingredients of epidemiology as highly provocative. These were "counting people in populations and medical knowledge." Does this mean that I am implying that all epidemiologists are or should be engaged in clinical practice? By no means; some of the most important contributions to epidemiology have been made by people who had no training or qualifications in medicine and others by people who had long since given up clinical practice. It must be said, however, that in these instances the ideas have usually come through contact with colleagues in the medical profession or by drawing on the capital of past personal medical experience.

My point is that epidemiology exists as an entity by fusing two sets of techniques that have their own independent life and being and aims and objects. The first of these is the group of survey techniques that entail counting people. These techniques, which I will call demographic statistics, are also used for a wide range of purposes that have little or nothing to do with medicine -namely, research in the social sciences, political opinion polls, market research, and so on. On the other hand, the development of medical science and of the knowledge of the disorders of bodily function and their prevention and treatment proceeds, although more restrictedly and more slowly than it otherwise would, without counting the people affected and relating them to definable populations. To put it in a nutshell, a clinician is an epidemiologist in so far as he employs the habit of thought which counts people and relates them to a definable population, and the demographic statistician is an epidemiologist in so far as he understands and exploits the opportunities of medical science, and applies his methods to them.

\section{Lack of encouragement}

Many of us hoped that the setting up in 1974 of the new specialty of community medicine would lead to a flowering of epidemiology in what is, after all, the country in which this 
subject originated. Sadly, so far at any rate, this has not happened. I detect two main reasons for this. The first is that, ironically, the founding fathers of community medicine overestimated the importance of the role that epidemiology would have in community medicine within the reorganised health service. Consequently, the only postgraduate training programmes that contain any formal element of epidemiology are linked with a career structure that has so far given little scope for the use of epidemiology. The posts of community physician and area and regional specialist are principally to do with day-today management and administration of the health services and aspects of planning that have relatively little to do with epidemiology. This frustrates the would-be epidemiologist.

A second reason why epidemiology is failing to flourish, I suggest, may be that the faculty of community medicine has not given sufficient attention to its relation with clinical practice and is tending to grow apart from it. Neither the present contract nor the proposed contract for specialists in community medicine does anything to encourage epidemiologists to remain in parttime clinical practice should they so wish: rather the reverse. The results of a recent survey that I carried out suggest that this policy is contrary to the aspirations of many trainees in community medicine, who see it as inimical to realising the objectives of their specialty and a discouragement to recruitment. But, most unfortunate of all, this policy separates those trained in epidemiology from an important source of insight and inspiration.

Even in universities, a career that combines both clinical practice and epidemiology, such as my own and that of a handful of others, is precarious and difficult to recommend to the young enthusiast because of the rigidity of postgraduate training programmes and lack of career opportunities. This is sad, because for me at least epidemiology is not a skill best left exclusively to those trained and in constant practice, as is ophthalmic surgery, for example, but, like biochemistry or immunology, it is a discipline of thought and method that should permeate the whole of clinical medicine. Thus its approach helps not only in recognising external causes, as I have shown in the examples that I have quoted, but also in critically evaluating treatment and developing a more balanced perspective of the natural history of disease than can usually be got from personal experience.

\section{Awakening interest}

Nothing I have said so far should be interpreted as suggesting that there is not an important place for specialists in epidemiology who devote the whole of their time to it. Indeed, I believe that it is urgent that a career structure should be created that encourages more of the men and women who have developed the appropriate enthusiasm and skills to stay in epidemiology without necessarily having to take on major administrative responsibilities as community physicians or as area or regional specialists in community medicine. This centre, with its special interest in industrial problems, could provide opportunities and important work for specialists in epidemiology as part of a team. Perhaps several centres like this, each with a different interest, should be created in different parts of the country. Evaluating geriatric services and orthopaedic prostheses come to mind as two areas urgently in need of a cohesive effort with epidemiological help, but there are many others.

But I will not end on a note of gloom or frustration. The other side of the coin is gleaming brightly. There is a real awakening of interest in epidemiology among the medical profession generally. The pioneer international seminars in cardiovascular epidemiology organised by my friend Geoffrey Rose for cardiologists attract many applicants, and Geoffrey Rose and David Baker's annual one-week course in clinical epidemiology at Southampton (now in its third year) can already claim graduates from most of the larger specialties. The creation of this Industrial and Community Health Research Centre by private subscription, for which I once again offer my congratulations and best wishes, is further remarkable evidence of this awakening.

It was Josiah Spode the younger who invented the recipe on which part at least of the prosperity and fame of the Potteries depends. He found that if you take fine china clay, add feldspar to it and a little bone ash, and place it in the furnace a miracle of transformation takes place. Likewise, if we take knowledge of the patterns of symptoms, signs, biological processes, and social influences that constitute medicine and add the habit of thought that counts people and relates them to definable populations, a different sort of transformation takes place and epidemiology comes into being. Whether we have thereby created something as beautiful as Staffordshire bone porcelain I doubt, but we have a product that is at least as serviceable and still much under-used.

\section{References}

${ }^{1}$ Morris, J N, Uses of Epidemiology. Edinburgh, Churchill Livingstone, 1975.

2 Batchelor, J R, Compston A, and McDonald, W I, British Medical Bulletin, 1978, 34, 279.

${ }^{3}$ Baker, G, Medical Transactions of the Royal College of Physicians of London, 1772 , p 175.

${ }^{4}$ Macbeth, R, fournal of Laryngology and Otology, 1965, 79, 592.

${ }^{5}$ Acheson, E D, et al, British Medical fournal, 1968, 2, 587.

6 Acheson, E D, Preventive Medicine, 1976, 5, 295.

7 Gregg, N M, Transactions of the Ophthalmological Society of Australia, $1941,3,35$.

${ }^{8}$ Case, R A M, and Hosker, M E, British fournal of Preventive and Social Medicine, 1954, 8, 39.

- Office of Population Censuses and Surveys, Mortality Statistics: area, 1976, Series DH5 No 3. London, HMSO, 1978.

${ }^{10}$ Office of Population Censuses and Surveys, Occupational Mortality, 1970-2. London, HMSO.

11 Barker, D J P, personal communication, 1978.

${ }^{12}$ Barker, D J P, et al, British Medical fournal, 1977, 1, 1181.

${ }_{13}$ Doll, R, British fournal of Industrial Medicine, 1955, 12, 81.

(Accepted 12 fanuary 1979)

\section{Is there any danger of contracting botulism from home-frozen food?}

Yes. There is always a danger that food prepared in the home, particularly but not exclusively canned, bottled, or smoked meat or fish, may not have been heated sufficiently to destroy the organisms. The temperature of a domestic deep freeze is certainly not low enough to kill them; and repeated reheating will add to the chances of any original contaminants surviving and growing.

Is there a suitable form of treatment that patients who suffer from acute anaphylactic reaction to wasp stings can carry round with them-perhaps some form of injectable adrenalin?

The Bee Association used to have an appropriate syringe for selfadministered adrenaline, but this is now no longer available for patients who are anaphylactically sensitive to bee or wasp stings. Those patients who are at risk from severe sting reactions should have available a disposable syringe and needles and a $1 \mathrm{ml}$ ampoule of adrenaline $1 / 1000$. Half of this ampoule should be given as a deep subcutaneous injection near to the sting site if this is possible. Patients should be fully instructed in self-administration. Tourniquets are usually not practical and are not advised. Since $80 \%$ of deaths are due to high airways obstruction, patients should carry with them a salbutamol bronchodilator spray such as asthmatic patients use.

The lives of only a small percentage of those who become anaphylactically sensitive to wasp stings are at risk-there have been 50 deaths from bee and wasp stings in 10 years in England and Wales. Commercially available whole-body wasp extracts for immunotherapy have low potency and are almost ineffective for treating severe allergic reactions from stinging insects. Recent experimental work suggests that in future venom must be used diagnostically and therapeutically in venom-allergic patients. 